\title{
Collegiate Trainees' Committee position on structured training
}

\section{Preamble}

In response to the Calman Report (Calman, 1993) the College must produce a policy on structured training initially addressing higher professional training. The College is also producing an educational strategy covering content and assessment of all the career grades. The Collegiate Trainees' Committee (CTC) considered these issues at its annual residential meeting in September 1994. The President, The Dean, Dr Harris and Dr J. Robertson, (Sub-deans) attended. Dr Harris is convenor of the College's Educational Strategy Working Party and Dr Robertson and $\mathrm{Dr}$ Davies (Chairman CTC) are members.

\section{Introduction}

Medical education starts from entry to medical school and continues until retirement, perhaps 47 years; in the words of the Edinburgh Declaration (Lancet, 1988) "a lifetime of continual learning". It is not therefore necessary to cram everything into seven years of postgraduate training, let alone three. The introduction of accredited, continuing professional development should encourage and formalise learning within the consultant grade and will probably necessitate some kind of 'logbook' for consultants.

The aims of the Calman Report were to reduce the length of training to about seven years, introduce the Certificate of Completion of Specialist Training (CCST), reduce the number of training grades to two, and introduce more structured training. Structured training for the higher professional training grade was seen to include annual reviews, appraisal and a mentor scheme. Calman outlined four themes that should be embraced in postgraduate training: flexibility, choice, competency and assessment on merit.

Training will extend from graduation to the award of the Certificate of Completion of Specialist Training. There should be yearly assessments of progress and trainees must have satisfactorily completed one year before they can move on to the next. On receiving the CCST the trainee should be equipped to take up a consultant post in the National Health Service of the UK as well as having European specialist status. Consultants in today's NHS require a wide range of skills including managerial, evaluative, supervisory and educative, in addition to a high level of clinical competence.

\section{General principles}

There is support among junior staff for the idea of structured training. This should include continuous assessment of competence, annual reviews, realistic goals, clear expectations of trainees, the standards to be achieved, and also clear expectations of their trainers.

We feel structured training should include the following.

(a) An educational contract specifying what should be achieved during a post in educational terms. This would be negotiated with the educational supervisor at the start of each post. It would include obligations on the trainer to provide training as well as on the trainee to complete it. This individual contract should be in addition to the contract between the Postgraduate Dean, Consultant and Provider Unit.

(b) Educational activities should normally take place during working hours.

(c) Individual programmes, tailored to trainees' needs, which address weaknesses and build on strengths. A tutor should take a long-term overview of a trainee's needs.

(d) Regular feedback on progress towards meeting educational objectives.

(e) Continuous assessment based on agreed, defined standards which have to be fulfilled (rather than an examination to pass) at each stage. There must be a satisfactory external appeals mechanism. Assessments may 
include audits of trainees' case-notes; videos of interviews; examples of care plans; clinical problem-solving; preparing a teaching package on a topic including written material.

(f) Annual reviews. These should be a collaborative exercise between trainee and educational supervisor aimed at developing an effective individual training programme. The intention is not to impede trainees in their progress to consultant posts or to introduce unnecessary hurdles. The outcome of a review should be to map out the next year's targets which may include extending training in areas not adequately covered in the past or gaining additional skills for those progressing well. It may rarely be necessary to ask trainees to repeat the content of part, or all of a year (but not in the same posts) before moving on. After the first year in psychiatry, it should be extremely rare to advise someone to change career.

(g) A twin track of new skills acquisition and consolidation of existing skills.

(h) Research skdlls and methodology teaching is essential for all trainees. The need for all trainees to complete original research is doubtful, other activities may be an appropriate substitute.

(i) Audit; all training schemes should introduce audit procedures to ensure that standards are set, maintained and improved. These would ideally be trainee led, all should have meaningful trainee participation.

(j) The MRCPsych examination; the College must produce a clear and realistic syllabus as a matter of urgency. With the introduction of more formal continuous assessment procedures the need for an examination in its current form should be reassessed. As assessment is introduced this may replace some or all of the current MRCPsych examination.

(k) Exit examination before award of CCST. We are strongly opposed to this. If the annual review process is properly implemented, the assessment process will be far superior to any examination.

\section{Structure of training grades}

There will be two training grades: general professional trainees comprising current senior house officers and registrars and higher professional trainees equivalent to the current senior registrars. The overall length of postgraduate training will be a minimum of seven years. The CTC unanimously supported the completion of four years of general professional training (GPT) (at least three of which should be in psychiatry) on taking up a higher professional training (HPT) post. To progress to higher training it would be necessary to pass the Membership Examination and undergo competitive interview. The current minimum of three years in HPT should be completed before eligibility for the CCST could be assessed. Any increase in the minimum time in HPT would seem perverse in the light of attempts to reduce the duration of training by improving its quality and structure. Terms and conditions for these grades have yet to be negotiated. It is planned eventually to move to a single training grade but until that time the most pragmatic structure is that suggested above. The introduction of better assessment and annual reviews, although intended primarily for the HPT grade, seems to offer a great deal to GPT trainees and is supported by the CTC.

\section{General professional training}

This should retain the strengths of the current rotational model in providing a wide range of sub-speciality experience at a variety of sites. The opportunity to spend time in other medical specialities, or general practice, for up to one year should be retained but the approved specialities should be reviewed. We would envisage a core and cluster model of training. The core would be general adult and old age psychiatry. Clusters include long-term mental illness and social and environmental treatments (may include rehabilitation, mental handicap, some community psychiatry posts); psychotherapeutically focused jobs (includes child and family therapy and general jobs with a special interest in psychotherapy, in addition to fulltime posts); liaison experience (may include old age, child and family liaison, neuropsychiatry); speciality including forensic, mental handicap, drug and alcohol, academic psychiatry.

The first year of GPT should focus on developing basic clinical skills in psychiatry such as interviewing, interpersonal and 
teamworking skills and basic counselling skills, physical treatments and the Mental Health Act. The first annual review should act as a filter to distinguish between those likely to succeed in psychiatry and those who should be redirected towards another speciality. Those trainees who wish to pursue research later in GPT need the time, resources and supervision to do so effectively. The growing availability of Masters courses with a research component could contribute to this. These should not, however, be compulsory. Some untversities, acting as monopoly suppliers, will not offer the mandatory instruction for the MRCPsych examination without trainees signing up for a Masters degree. This is unlikely to be in the best interests of every trainee, particularly when opportunities to take higher qualifications in the psychotherapies, and also management, are increasingly an option. The exam will continue to mark the end of GPT but with a clear and realistic syllabus. The current position where the examination hurdle dominates training to the detriment of wider issues needs to be addressed. There should also be a review of all the current recommendations and policies on training (including the CTC's) so that a realistic curriculum can be developed. There is a tendency for every special interest group in the College to produce training recommendations on their own 'pet' subject to the confusion and demoralisation of trainees.

The introduction of continuous assessment and annual reviews focusing on clinical skills should be guided by the principles above. This should be in the context of explicit competencies to be achieved and with clear review criteria, peer review and an external appeal mechanism. The entry of candidates for the exam should be more than the paper exercise it has become and could be incorporated into the annual review procedure. Those entered should be fit and proper people to become Members of our College and, more importantly, to treat psychiatric patients.

The gap between GPT and HPT needs to be closed to allow training to progress quickly and efficiently.

\section{Higher professional training}

There is a general feeling that more structure needs to be provided for individual trainees' HPT programmes. Once over the hurdle of the examination the focus of training needs shifts and is harder to define. The development of greater clinical autonomy is essential as are the clinical skills of the chosen sub-specialty. Today's consultants need a wide range of skills. These include supervision of staff, both medical and non-medical; teaching skills; management skills, self management as well as service management; evaluative skills including audit and research. There is also a need to develop skills to continue one's medical education in a self-directed way as a consultant. The use of the day a week research and private study time also needs some thought. Research currently seems to hold a predominance in terms of career progress that is not justified in relation to suitability to become an NHS consultant. The CTC feels that other areas such as teaching skills, management and political skills, psychotherapy, and the development of areas of additional clinical competence, should carry equal weight at appointment committees for NHS posts. The time currently spent on research could be spent on these other activities. Any research undertaken should be properly supervised and of demonstrable benefit. Too many trainees have little to show for their day a week of research with none or poor quality publications. As this time accounts for $20 \%$ of HPT it is important that it is used effectively and greater flexibility in its allocation may aid this. For example, six months of full-time work on a specific project may be more effective than a day a week. A rigorous grounding in research methodology and interpretation is considered necessary for all consultants.

\section{Flexdble training}

Flexible training has an important and growing place in psychiatric education. The availability and ease of access to flexible training needs to be improved. Flexible training should be available to those who want it and not 'means tested' on domestic or health criteria. The rest of this document, with modification of time criteria, should apply to flexble training.

\section{Overseas Doctors Training Scheme}

As Overseas Doctors Training Scheme (ODTS) trainees should already have psychiatric experience, the relevance of four years' GPT to their training is questionable. Based on 
their assessed competence arrangements should be made to allow them to spend part of their time in higher training posts after a shorter period of GPT. Due to the time requirements before sitting the membership, and the Home Office limit of four years, passing the membership is not a practical test of readiness for HPT in ODTS trainees.

\section{Action points}

(a) The exam syllabus needs to be made clear, realistic and public.

(b) Further reduction of the bottleneck between GPT and HPT is needed. This will allow trainees to avoid wasting time waiting for a HPT post.

(c) Educational contracts need to be developed as a two-way process between consultants and trainees.

(d) Continuous clinical assessment needs to be introduced with explicit standards to be achieved and with feedback and corrective mechanisms built in. In addition an annual overview of progress should be introduced to assess the progress in the previous year and set targets for the next.

(e) Trainee-owned logbooks should be introduced as part of the assessment and review process. They should be used to identify achievements and deficits in training to be remedied rather than a 'why haven't you done this?' approach. Their use should be in context of an overview of the trainee's past, current and future career needs.

(f) The flexibility of speciality experience, psychiatric and other medical, in GPT, should be retained with a move to a balanced core and cluster approach.

(g) The ability to evaluate research methodology is essential for all trainees but not all trainees in HPT need to participate in original research. There are other activities of equal value in preparation for the consultant grade. Those who participate in research require adequate supervision of projects with demonstrable benefit and the resources to enable completion. (h) All training schemes need to introduce internal audit procedures to assess the quality of their training and trainers as well as trainee achievements. These should have strong trainee participation, ideally trainee led.

(i) The College needs to review urgently the multiplicity of training documents in existence to produce a realistic curriculum for the seven years of postgraduate psychiatric training.

(j) The time and financial implications of introducing these changes need to be costed so that guidance to purchasers (provider units and post-graduate deans) can be prepared. Tutors, educational supervisors and external assessors all need protected educational time recognised by their employing trusts and the Postgraduate Dean.

\section{Acknowledgements}

Thanks to all members of the CTC and the College officers who participated in the meeting and especially to Dr Mike Harris, convenor of the Educational Strategy Working Group, whose document was the basis of much of the discussion.

\section{References}

CALMAN, K. C. (1993) Hospital Doctors: training for the future. The Report of the Working Group on Specialist Medical Training. London: HMSO.

The Edinburgh Declaration (1988) Lancet, 2464.

Steffan Davies, Chairman; Phil Davison, Vicechairman; Cliff Sharp, Honorary Secretary; Annie Hall, Tim Oakley, Gary Sullivan, working group convenors, Collegiate Trainees' Committee, Royal College of Psychiatrists

\section{Authors' note}

Since our initial meeting in September 1994 substantial progress has been made on some of the 'Action points', particularly the production of an exam syllabus. 